\title{
Liver volume estimation using ultrasound scanning
}

GEORGE W RYLANCE, TERENCE A MORELAND, MICHAEL D COWAN, AND DAVID C CLARK

Department of Child Health and Department of Pharmacology and Therapeutics, University of Dundee, and Department of Radiology, Ninewells Hospital, Dundee

SUMMARY Liver volume was determined by an ultrasonic scanning technique in 14 healthy children. There was a linear decrease in liver volume per unit body weight with increasing age throughout childhood.

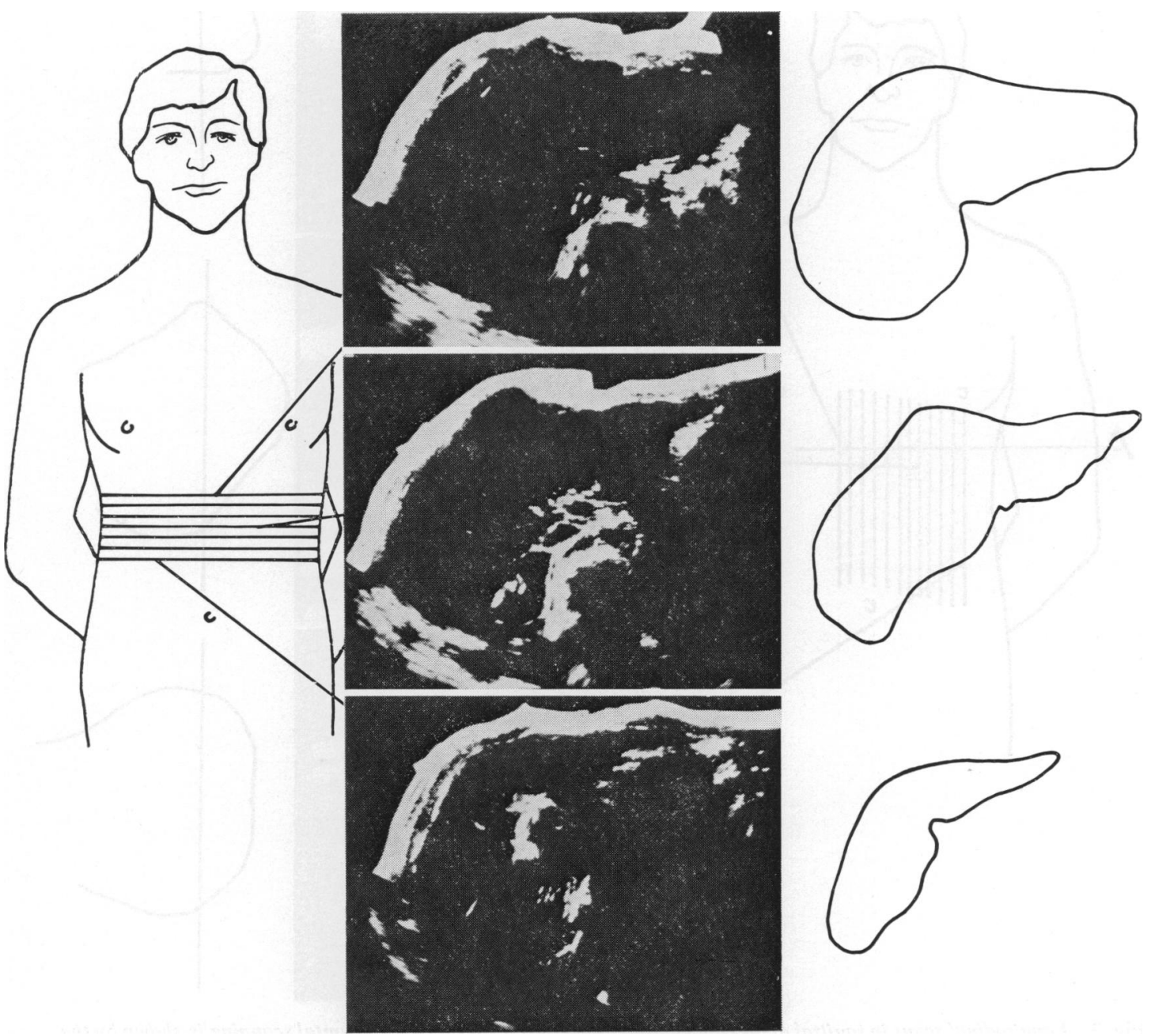

Fig. 1 Serial transverse scans of abdomen. 
It may be difficult to determine whether a child's liver is enlarged. Measurements of the projection of the liver edge below the diaphragm margin using percussion and palpation, and the length of the vertical axis of the liver using $x$-radiography, have been used as indices of liver size, and have been determined in large groups of children. ${ }^{12}$ However, both these methods assess liver size in one dimension only, and as the liver is an irregularly-shaped organ with pronounced inter-individual variation in shape, it cannot be assumed that such assessments will accurately represent overall liver size. For this reason, liver volume is more likely to represent liver size, and because a change in shape may not necessarily be equal in all directions, change in liver volume is more likely to reflect such change.

Liver volume may therefore be a more useful clinical parameter and this can be measured by scintiscanning after the administration of a radioisotope. $^{3}$ Alternatively, it can be determined by

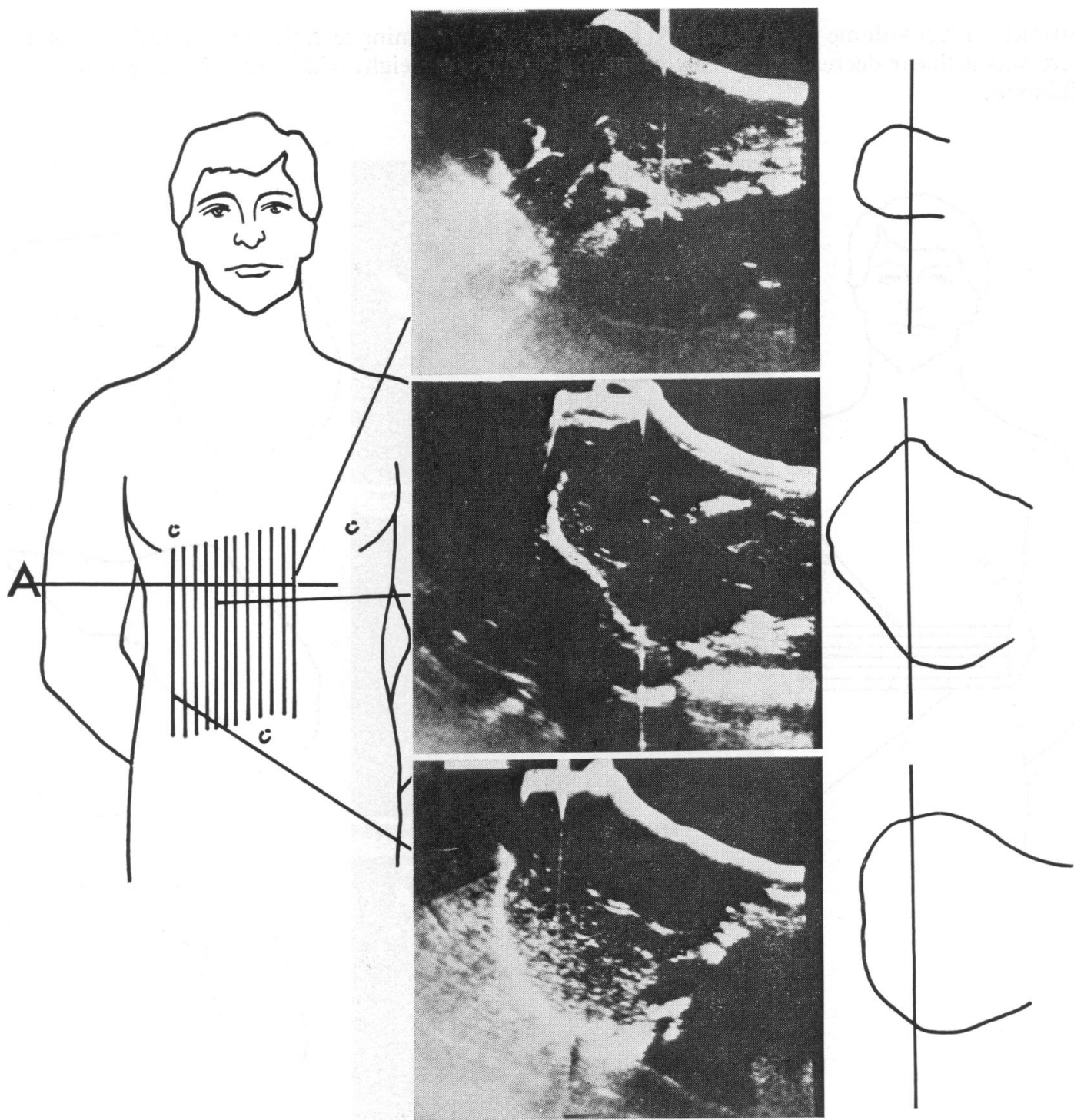

Fig. 2 Longitudinal scans in sagittal plane (upper limit of liver visualisation on horizontal scanning is shown by the horizontal line A). 
ultrasonic scanning, a method which is non-invasive, non-isotopic, and one that has been used in adults. ${ }^{4-6}$

The present study was carried out to determine the feasibility of estimating liver volume in children of different ages by the ultrasonic scanning method of Roberts et al. ${ }^{6}$

\section{Methods}

Fourteen normal healthy children, 5 boys and 9 girls aged between 5 months and 14 years, were studied. Informed parental consent was obtained and the study was approved by the local hospital ethical committee. None of the children was receiving drugs.

Liver volume was determined by recording serial transverse scans of the abdomen at $1-\mathrm{cm}$ intervals from the inferior limit of the liver to the upper limit at which the liver outline could be clearly visualised (Fig. 1). The liver above this level was defined by recording serial longitudinal scans in a sagittal plane at the same interval (Fig. 2). The line (A) showing the upper limit reached on horizontal scanning is clearly shown in Fig. 2.

The scans were photographed, and the liver outline traced, photocopied (Figs 1 and 2), and cut from the paper. The area of each liver section was determined by dividing the weight of the paper section by the known weight per unit area of the paper. Total liver volume was derived by summating the calculated areas and multiplying by the magnification factor used.

The reproducibility of the method was assessed by determination of the coefficients of variation in 4 children aged between 6 and 13 years. Three had 2 scans on separate occasions within a week, while the fourth had 3 separate scans within the same period.

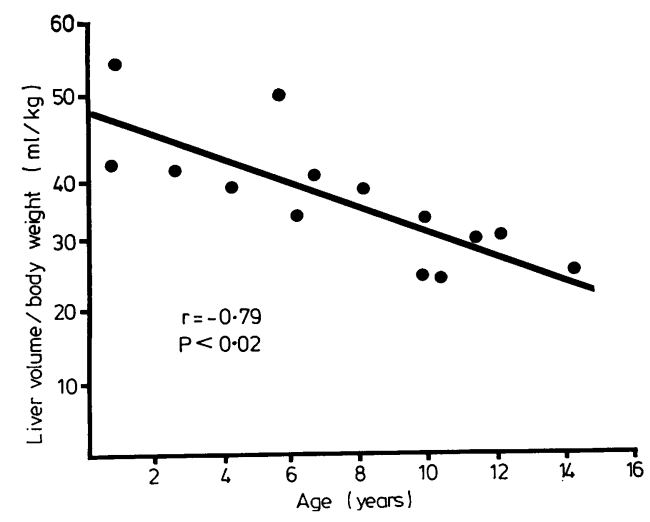

Fig. 3 Liver volume per unit body weight and age.
Table Liver volumes and coefficients of variation in 4 children having more than one scan

\begin{tabular}{|c|c|c|c|c|c|c|}
\hline \multirow[t]{2}{*}{ Case } & \multirow{2}{*}{$\begin{array}{l}\text { Age } \\
\text { (years) }\end{array}$} & \multicolumn{4}{|c|}{ Liver volume $(\mathrm{ml})$} & \multirow{2}{*}{$\begin{array}{l}\text { Coefficient of } \\
\text { variation }(\%)\end{array}$} \\
\hline & & Ist & $2 n d$ & $3 r d$ & $M e a n \pm S D$ & \\
\hline $\begin{array}{l}1 \\
2 \\
3 \\
4\end{array}$ & $\begin{array}{r}6 \\
13 \\
9 \\
8\end{array}$ & $\begin{array}{r}392 \\
1280 \\
996 \\
232\end{array}$ & $\begin{array}{r}400 \\
1364 \\
1146 \\
197\end{array}$ & 410 & $\begin{aligned} 401 & \pm 9 \\
1322 & \pm 59 \\
1071 & \pm 106 \\
215 & \pm 25\end{aligned}$ & $\begin{array}{r}2 \cdot 2 \\
4 \cdot 5 \\
9 \cdot 9 \\
11 \cdot 7\end{array}$ \\
\hline
\end{tabular}

\section{Results}

Liver volume per unit body weight correlated significantly with age $(r=0.79, P<0.02)$, and the relative volume in the first year of life was almost twice that at 14 years (Fig. 3). There was no significant correlation between liver volume per unit surface area or per unit length, and age.

The mean \pm SD coefficient of variation in the 4 children having two or more scans was $7 \cdot 1 \pm 4 \cdot 5 \%$ (Table).

\section{Discussion}

The accurate assessment of liver size is an important and often difficult part of the clinical examination of many patients. Estimation of liver size by percussion and palpation is inaccurate and underestimates lesser abnormalities. ${ }^{7}$ Ultrasonic scanning provides a rapid, accurate, and convenient method for measuring liver volume which does not require radioisotope administration. The rapidity and convenience of the method would probably be increased with the use of a computer fitted with a graphic tracing device to measure and sum the appropriate area of the scans.

We assessed the feasibility of using an index scan or scans at different levels and in different directions in order to reduce the total number of scans required. No correlation between a single scan or equation using a limited number of scans, and liver volume was found. This may reflect significant interindividual differences in liver shape and position.

Post-mortem organ weight studies have demonstrated that per unit body weight, children have heavier livers than adults. ${ }^{8-10}$ Fig. 4 shows the results of these investigations where liver weight is expressed per unit body weight and per unit body surface area, and demonstrates the wide variability between such studies. During childhood, liver weight declines compared with body weight and increases per unit surface area but the years over which these changes occur vary greatly between the studies. This study shows that there is a linear decrease in liver volume per unit body weight with increased age throughout childhood. 

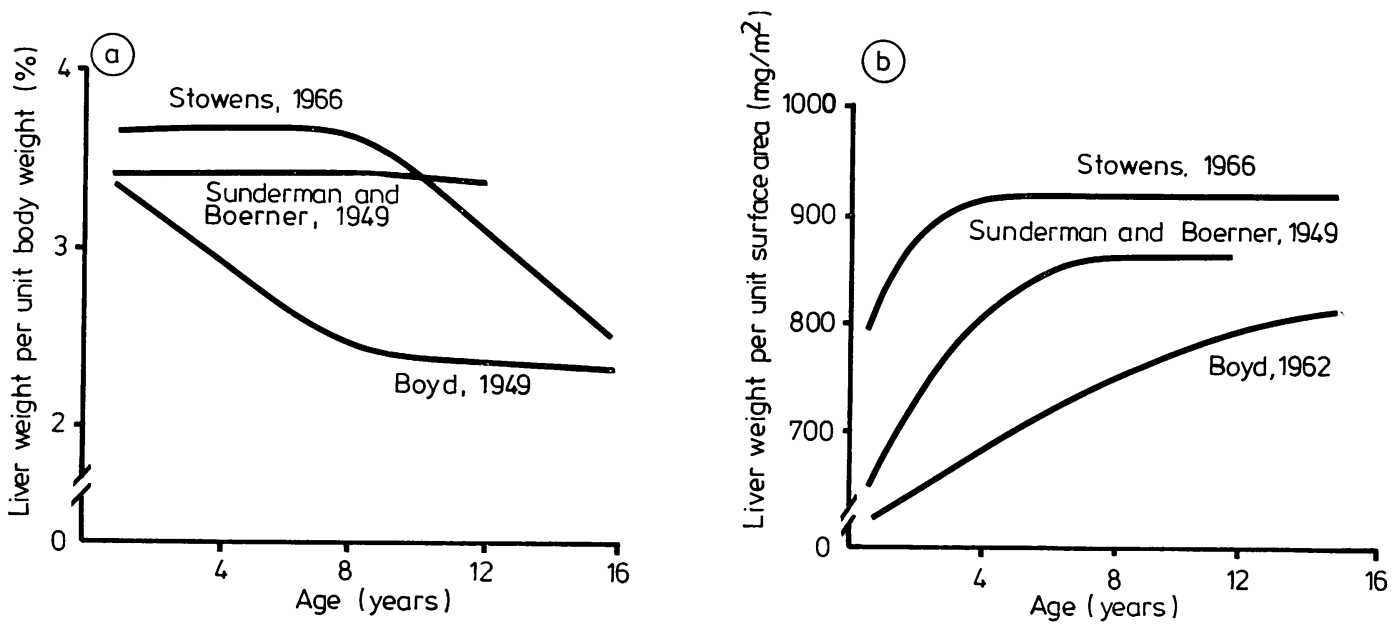

Fig. 4 Change in (a) liver weight per unit body weight (\%) and (b) liver weight per unit surface area $\left(\mathrm{mg} / \mathrm{m}^{2}\right)$ with age.

This ultrasonic scanning method of estimating liver volume may have wide application in paediatric practice in differentiating normal from abnormally sized livers, in monitoring the change in liver volume in poorly controlled disease states-for example, diabetes mellitus - and in relating liver size to drug metabolising ability.

\section{References}

1 Deligeorgis D, Yannakos D, Doxiadis D. Normal size of liver in infancy and childhood. $X$-ray study. Arch Dis Child 1973; 48: 790-3.

2 Deligeorgis D, Yannakos D, Panayotou P, Doxiadis S. The normal borders of the liver in infancy and childhood. Clinical and $x$-ray study. Arch Dis Child 1970; 45: 702-4.

3 Yagan R, MacIntyre W J, Christie J H. Estimation of liver size by the multiple cut off scintillation scanning technique. AJR 1962; 88: 289-95.

4 Kardel T, Holm H H, Rasmussen S N, Mortensen T. Ultrasonic determination of liver and spleen volumes. Scand J Clin Lab Invest 1971 ; 27 : 123-8.

5 Rasmussen $\mathbf{S}$ N. Liver volume determination by ultrasonic scanning. Br J Radiol 1972; 45 : 579-85.
- Roberts C J C, Jackson L, Halliwell M, Branch R A. The relationship between liver volume, antipyrine clearance, and indocyanine green clearance before and after phenobarbitone administration in man. Br J Clin Pharmacol 1976; 3: 907-13.

7 Sullivan S, Krasner N, Williams R. The clinical estimation of liver size: a comparison of techniques and an analysis of the source of error. Br Med J 1976; ii: 1042-3.

8 Sunderman F W, Boerner F, eds. Normal values in clinical medicine. Philadelphia: Saunders, 1949.

9 Boyd E. Organ weights from birth to maturity: man, North American. In: Altman P L, Dittmer D S, eds. Growth, including reproduction and morphological development. Biological Handbooks. Washington: Federation of American Societies for Experimental Biology, 1962: 346-8.

10 Stowens D. Pediatric pathology, second edition. Baltimore: Williams \& Wilkins, 1966: 1-9.

Correspondence to Dr G W Rylance, Children's Hospital, Ladywood Middleway, Ladywood, Birmingham B16 8ET.

Received 16 April 1981 